\begin{tabular}{cc|c}
\hline Tar. Bil.Der. & Tarım Bilimleri Dergisi & Journal of Agricultural Sciences \\
& $\begin{array}{c}\text { Dergi web sayfası: } \\
\text { www.agri.ankara.edu.tr/dergi }\end{array}$ & $\begin{array}{c}\text { Journal homepage: } \\
\text { www.agri.ankara.edu.tr/journal }\end{array}$ \\
\hline
\end{tabular}

\title{
Tokat Kazova Topraklarının Yarayışlı Fosfor Düzeyinin Jeoistatistik Tahmin ve Simulasyon Metodlarıyla Modellenmesi ve Haritalanması
}

\author{
Fevzi AKBAŞ ${ }^{\mathbf{a}}$ \\ ${ }^{a}$ Konya Toprak Su ve Çölleşme İle Mücadele Araştırma İstasyonu Müdürlüğü, Meram, Konya, TÜRKIYYE
}

\section{ESER BÍLGISI}

Araştırma Makalesi — Bitkisel Üretim DOI: 10.1501/Tarimbil_0000001193

Sorumlu Yazar: Fevzi AKBAŞ, e-posta: yavuzz42@hotmail.com, Tel: +90(332) 3596612 / 237

Geliş tarihi: 22 Eylül 2011, Düzeltmelerin gelişi: 07 Mart 2012, Kabul: 13 Mart 2012

\begin{abstract}
ÖZET
Tarım alanlarında toprak özelliklerinin değişiminin belirlenmesi ve haritalanması; planlama, etkili ve sürdürülebilir amenajmanı ve değișimin zamansal ve mekânsal olarak izlenmesini mümkün kılar. Bu çalışmada toprakların yarayışı fosfor (YP) içeriğinin iki farklı jeoistatistik metod ile haritalanması ve elde edilen sonuçlardaki farklılıkların ortaya konulması amaçlanmıştır. Haritalamada ordinary kriging $(\mathrm{OK})$ ve ardış1k gauss simulasyonu (AGS) yöntemleri kullanılmıştır. Çalışma, Tokat'ın en büyük ve Türkiye'nin önemli tarımsal potansiyele sahip ovalarından biri olan 20,656 ha büyüklüğündeki Kazova'da yürütülmüştür. Rastgele örnekleme metodu ile iki derinlikten $(0-30 \mathrm{~cm}$ ve $30-60 \mathrm{~cm})$ toplam 800 bozulmuş toprak örneği alınmıştır. Çalışma alanında ortalama yarayışlı fosfor üst toprakta $14.18 \mathrm{mg} \mathrm{kg}^{-1}$ ve alt toprakta $8.87 \mathrm{mg} \mathrm{kg}^{-1}$, dır. Ordinary Kriging yöntemine göre Kazova üst topraklarının \%11.56'lık kesiminde yarayışlı fosfor düzeyi az, \%82.16'sında yeterli ve \%6.28'inde ise fazla olarak bulunmuştur. On adet simülasyonun ortalamasını alındı̆̆ı AGS yöntemi ile ovanın \%9.98'lik kesiminde az, \%86.27'inde yeterli ve \%3.75'inde ise fazla olarak sınıflandırılmıştır. Alt toprakta ise $(30-60 \mathrm{~cm})$ yarayışı fosfor miktarlarını haritalamada kullanılan metotlar arasındaki farklılıklar üst toprağa göre daha fazladır. Arazi boyunca fosfor seviyelerini ve bu seviyelere karşllık gelen değişimleri gösteren haritalar gübreleme konusunda karar alıcıların gübre miktarı planlaması ve çevre açısından risklerin modellemesinde potansiyel kullanım alanına sahiptir.

Anahtar sözcükler: Yarayışlı fosfor; Jeoistatistik; Ordinary kriging; Ardışık gauss simülasyon; Değişkenlik
\end{abstract}

\section{Modelling and Mapping Available Phosphorus Level of Tokat Kazova Soils with Geostatistical Estimation and Simulation Methods}

\section{ARTICLE INFO}

Research Article - Crop Production

Corresponding author: Fevzi AKBAŞ, e-mail: yavuzz42@hotmail.com, Tel: +90(332) 3596612 / 237

Received: 22 September 2011, Received in revised form: 07 March 2012, Accepted: 13 March 2012

\section{ABSTRACT}

Determining and mapping the variability of soil properties ensures planning, effective and sustainable management, and monitoring spatial and temporal variability in agricultural areas. The objectives of this study were to model and map available $\mathrm{P}$ level of soils using two different geostatistical methods and to interpret differences of results of 
two methods. Ordinary kriging (OK) and Sequential Gaussian Simulation (SGS) methods were used in mapping. This study was carried out in the Kazova (20,656 ha), largest plain in Tokat and one of the prominent production area of Turkey. Eight hundred soil samples were collected in two depths $(0-30 \mathrm{~cm}$ and $30-60 \mathrm{~cm})$. Mean available phosphorus of study area were $14.18 \mathrm{mg} \mathrm{kg}^{-1}$ in surface soil and $8.87 \mathrm{mg} \mathrm{kg}^{-1}$ in subsurface soil. Based on maps prepared with ordinary kriging $11.56 \%$ of surface soils of Kazova contained low available P, $82.16 \%$ and $6.28 \%$ of soil had sufficient and excessive available P levels, respectively. Maps of SGS method (mean of 10 simulations) showed that $9.98 \%$ of surface soils of Kazova had low available P level. While $86.27 \%$ of the surface soil contained sufficient available P and $3.75 \%$ of soils was classified as excessive. For the subsoil of Kazova (30-60 $\mathrm{cm}$ ), dissimilarities between two mapping methods were higher. Different level of available P and location of these levels in the maps prepared with these methods have a potential usage of decision-makers to plan amount of fertilizer and risk modeling.

Keywords: Available phosphorus; Geostatistics; Ordinary kriging; Sequential saussian simulation; Variability

(C) Ankara Üniversitesi Ziraat Fakültesi

\section{Giriș}

Bitki için mutlak gerekli olan ve makro besin elementi olarak sınıflandırılan fosfor, diğer makro besin elementleri azot ve potasyum ile birlikte değerlendirildiğinde, topraktaki miktarı ve hareketliliği en düşük olan ve bitki gelişimini sinırlandırandır. (Shenoy \& Kalagudi 2005; Ryan \& Rashid 2005). Toprakların toplam fosfor miktarı 20 ile $1000 \mathrm{mg} \mathrm{kg}^{-1}$ arasında değişir. Mineral topraklarda toplam fosforun $\% 15$ ile 85 'i (ortalama \%50) inorganik formdadır (Tisdale et al 1993). Topraklarda toplam fosfor miktarı yüksek olmasına rağmen bitkiye yarayışlı miktarı kullanılan ekstrakte ediciye bağlı olmakla birlikte oldukça düşük olup genellikle olup, $8-25 \mathrm{mg} \mathrm{kg}^{-1}$ arasındadır (Alpaslan et al 1998). Bitkiye yarayışlı fosfor miktarını toprağın kireç, demir ve alüminyum içeriği, organik madde, kil ve $\mathrm{pH}$ düzeyi etkilemektedir. Toprağa uygulanan fosforlu gübrelerin yaklaşık $\% 15^{\prime} \mathrm{i}$ bitkiler tarafindan alınabilmekte, kalan kısım topraklarda fiske olmakta ya da adsorpsiyon ve çökelme yoluyla veya organik bileşikler oluşturarak bitkilerin alamayacağı formlara dönüşmektedir (Brady 1990). Bitkiler fosforu ana materyalden toprağa gelen fosfordan (bu miktar kritik toprak çözeltisi konsantrasyonunu sağlamada yetersizdir) ve genellikle toprağa ilave edilen organik ve inorganik gübrelerden almaktadırlar.

Ülkemiz toprakları iklim özellikleri, jeolojik yapısı ve coğrafi konumundan dolayı $\mathrm{pH}$ değerleri 7'nin üstünde, yüksek kil, kireç ve düşük organik madde içeriklerine sahiptirler (Dinç et al 1988;
Eyüpoğlu 1999). Belirtilen özelliklere sahip topraklarda fosforun bitkilere yarayışlılığı önemli ölçüde düşüktür (Tisdale et al 1993; Shenoy \& Kalagudi 2005). Eyüpoğlu (1999), Türkiye toprakları verimlilik envanteri çalışmasında yarayışlı fosforun (Olsen P) toprakların \%58'inde bitkiler için düşük düzeyde $\left(<6 \mathrm{~kg} \mathrm{P}_{2} \mathrm{O}_{5} \mathrm{da}^{-1} ;<\right.$ $10.8 \mathrm{mg} \mathrm{kg} \mathrm{kg}^{-1} 250$ ton $\mathrm{da}^{-1}$ toprak kabul edildiğinde) olduğunu bildirmektedir. Son yıllarda yapılan çalışmalarda (Erzurum, Bursa, Van ve Kastamonu illerindeki tarım arazileri ) sırasıyla ortalama $30.41,24.79,8.88$ ve $12.15 \mathrm{mg} \mathrm{kg}^{-1}$ yarayışlı fosfor içeriği bildirilmiştir (Turan et al 2010; Yıldız \& Bilgin 2008; Çimrin \& Boysan 2006; Taban et al 2010). Bu çalışmalarda Bursa ili tarım arazilerinde en yüksek $101.88 \mathrm{mg} \mathrm{kg}^{-1} \mathrm{ve}$ Erzurum'da $73.05 \mathrm{mg} \mathrm{kg}^{-1}$ yarayışlı fosfor değerleri dikkat çekmektedir (Turan et al 2010; Yıldız \& Bilgin 2008).

Bu çalışmaya da konu olan Tokat yöresinden alınan 4195 toprak örneğinin \% 73.3'ünde yarayışlı fosfor (YP) miktarı çok az ve az $(<6 \mathrm{~kg}$ $\mathrm{P}_{2} \mathrm{O}_{5} \mathrm{da}^{-1}$; yaklaşık $<10.8 \mathrm{mg} \mathrm{P} \mathrm{kg}^{-1}$ ) olarak rapor edilmiştir (Eyüpoğlu 1999). Tokat, Toprak ve $\mathrm{Su}$ Araştırma Enstitüsü laboratuarında 2000 ile 2003 y1lları arasında yapılan 6889 adet çiftçi toprak örneğinin \%53'ünde (3682 örnek) fosfor çok az ve az olarak belirlenmiştir (Tetik \& Oğuz 2004). Diğer bir çalışmada Kazova'da tarım alanlarında YP düzeyini ortalama $25 \mathrm{mg} \mathrm{kg}^{-1}$ (17 ile $33 \mathrm{mg}$ $\mathrm{kg}^{-1}$ ) olduğu bildirilmektedir (Saltalı et al 2004). Bilinçsiz gübreleme neticesinde Kazova topraklarında fosfor birikimini rapor eden Saltalı et al (2004) 30 farklı noktadan toprak örneklemesi 
yapmışlardır. Farklı kullanım türlerini de dikkate alan daha yoğun bir örnekleme ile Kazova tarım arazilerinin YP düzeylerinin ortaya konulmas1 gerekmektedir.

Toprakların değişkenliğinin belirlenmesi, izlenmesi ve yüksek ayrıntı düzeyinde veriye gerek duyan hassas tarım uygulamalarında enterpolasyon teknikleri kullanarak haritalar üretilmektedir. Toprak biliminde yeni ve farklı bir yaklaşıma sahip jeoistatistik yöntemler 1980 sonrası dönemde öne çıkmış ve toprak haritalarının hazırlanmasında yaygın olarak kullanılmaya başlanmıştır.

Kriging yöntemi ile yapılan tahmin haritaları, lokal detayları yumuşatma eğilimindedir ve bu durum veri setindeki yüksek değerlerin daha düşük, düşük değerlerin ise daha yüksek tahmin edilmesine neden olmaktadır. Bunun sonucu kriging tahmini ile elde edilen tahmin değerleri, veri setinden farklı temel istatistik değerlere (ortalama, minimum ve maksimum) sahiptir. $\mathrm{Bu}$ nedenle, kriging yöntemi ile hazırlanan haritaların arazide yüksek kirlilik veya besin elementi zenginleşmesi belirlenmesi gibi uygulamalarda yani veri setinde yüksek değerlerin varlığında yanlış ve eksik değerlendirmelere yol açtığı için kullanılmaması tavsiye edilmiştir (Goovaerts 1999; Goovaerts 2001; Zhao et al 2009).

Harita üretiminde kullanılan jeoistatistik simülasyon metotları (spatial stokhastik simülasyonlar) tahminlerin belirsizliği konusunda alternatif bir kavram ortaya koymaktadır. Krigingden farklı olarak simulasyonlar lokal hata varyansını minimize etmez, örnek noktalarındaki değerleri kabul ederek örnek histogramı ve semivariogram modeli gibi istatistikleri yeniden üretmeyi amaçlar. Bu yöntemler ile elde edilen çıktılar istenilen sayıda birbirine alternatif realizasyonlardır. $\mathrm{Bu}$ özellikleriyle simulasyon teknikleri arazi ölçüm değerlerinin korunmasının istendiği jeoistatistik çalışmalarda kriging yöntemlerine tercih edilmektedir (Grunwald et al 2007).

Ardışık Gauss Simulasyonu (AGS) toprakta kurşun (Lin et al 2001), çinko (Lin \& Chang 2000), organik madde ve besin elementleri (Zhoa et al 2009), toplam fosfor miktarı (Grunwald et al 2004), ağır metal ve mikro element (CaridadCancela et al 2005), kadmiyum (Meirvenne \& Goovaerts 2001) ve yer alt1 suyunun hidrolik iletkenliğinin (Lin et al 2001) haritalanmasında kullanılmıştır. $\mathrm{Bu}$ araştırıcıların kriging metodu ile üretilen haritaların yaygın olarak gözlenen sonuçları yumuşatma etkisinden dolayı basit uzaysal yapıyı ortaya koymakta eksik kaldığı ve detayları yakalayamadığını, simulasyon tekniklerinin bu konuda daha doğru sonuçlar verdiğini vurgulamışlardır.

$\mathrm{Bu}$ çalışmada, ülkemizin önemli tarımsal üretim merkezlerinde biri olan Tokat Kazova topraklarının bitkiye yarayışlı fosfor (YP) miktarlarının değişimini belirlemek, ordinary kriging ve ardışık gauss simulasyonu olmak üzere iki farklı haritalama yöntemi ile haritalayıp sonuçlar arasındaki farklıkları ortaya koymak amaçlanmıştır.

\section{Materyal ve Yöntem}

\section{1. Çalışma alanı}

Çalışmanın yürütüldüğü Kazova çoğunlukla tarımsal üretimi sınırlayıcı bir problemi olmayan derin toprakların yer aldığı ve düz düze yakın topografyaya sahip verimli bir ovadır. Büyük bir bölümü, Yeşilırmak nehrinin çok uzun sürede getirdiği malzemeleri depolaması neticesinde oluşan Kazova'da; buğday, şeker pancarı, mısır (birinci ve ikinci ürün olarak), domates, fasulye ve çeşitli sebzeler yanında meyvecilikte yoğun bir şekilde yapılmaktadır.

Bu çalışma için Tokat-Kazova bölgesinde să̆ sahil ve sol sahil sulama kanalları arasında 20,656 ha büyüklüğünde bir alanın 2006 yılı Ekim ve Kasım aylarında toprak örneklemesi yapılmıştır (Şekil 1). Toplam 400 noktadan, "rasgele örnekleme metodu" kullanılarak iki farklı derinlikten $(0-30 \mathrm{~cm}$ ve $30-60 \mathrm{~cm})$ toprak örnekleri alınmıştır. Coğrafi koordinatlar GPS ( \pm $3 \mathrm{~m})$ yardımıyla belirlenmiştir. Ortalama örnekleme mesafesi $460 \mathrm{~m}$, yaklaşık örnek yoğunluğu 50 ha/örnek ve en düşük örnekleme mesafesi ise $100 \mathrm{~m}$ 'dir. 


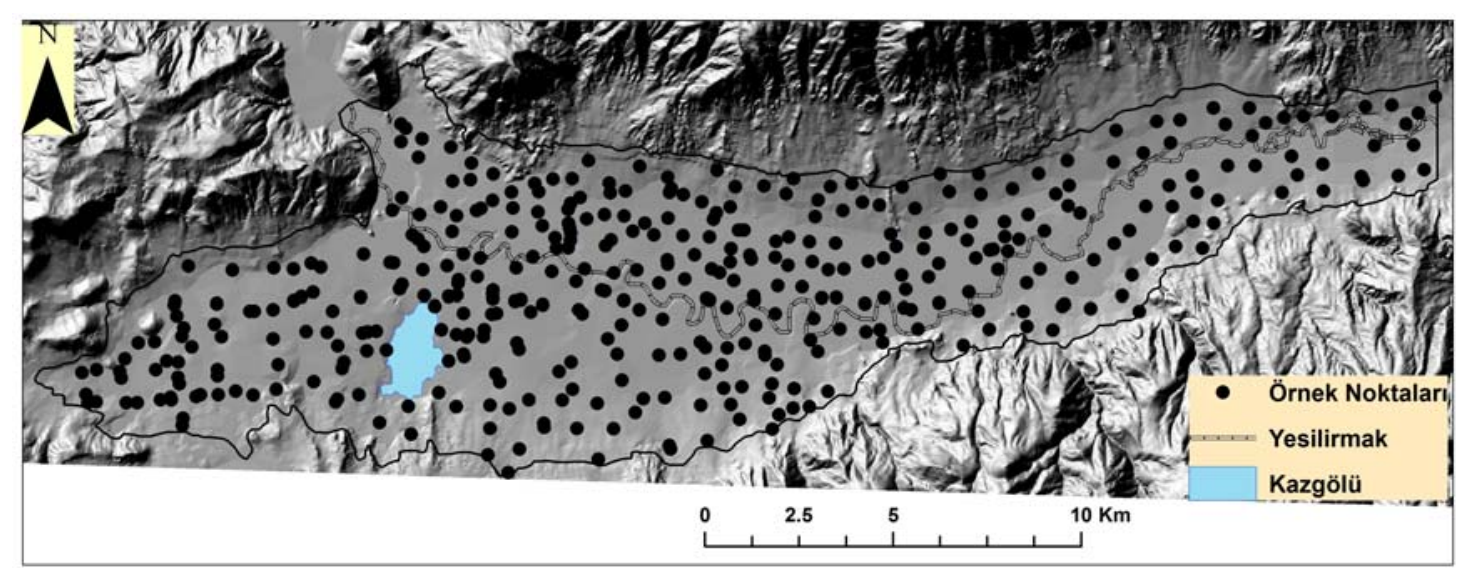

Şekil 1-Çalışma alanı ve örnekleme noktaları

Figure 1-Study area and sampling points

Orta Karadeniz bölümünün iç kısımlarında yer alan Tokat ili, Karadeniz iklim özellikleriyle İç Anadolu'daki step (kara) ikliminin etkisi altındadır. Tokat Meteoroloji İstasyonu kayıtları esas alındığında yıllık ortalama sıcaklığı $12.4^{\circ} \mathrm{C}$ olup yıllık ortalama yağış miktarı ise $446 \mathrm{~mm}$ (30 yıllık ortalama) olup en çok yağış, ilkbahar mevsiminde en az yağış ise yaz mevsiminde düşmektedir. (DMI 2007). Bu değerlere göre toprak sicaklık rejimi Mesic ve nem rejimi de Ustic olarak sinıflandırılmaktadır (Soil Survey Staff 1999).

Kazova Eosen'de meydana gelmiş bir çöküntü alanıdır. Genelde düz olan çalışma alanının denizden olan yüksekliği 535-650 m arasında değişmekte olup, ova doğu-batı istikametinde uzanmaktadır. Ayrıca ovanın güney ve kuzeyinden Yeşilırmak'a doğru eğimli bir topografya yer almaktadır. Kuzey yamaçlarda çoğunlukla metamorfik kayaçlar (Paleozoik şistler) ile ofiyolitik seri bulunur. Güney yamaçlarda ise metamorfik kayaçlar ile Üst Permiyen yaşlı kireç taşları yer almaktadır (Novinpour 1993). Genel itibari ile Kazova Yamaçlar, Etek birikinti Düzlükleri ve Ova Tabanı olmak üzere üç jeomorfolojik ünite bulunmaktadır ve çalışma alanında yamaç araziler yer almamaktadır.

Çalışma alanında aluviyal ve koluviyal olmak üzere genel anlamda iki grup toprak bulunmaktadır. Her bir örnekleme noktasından iki derinliklerinden alınan bozulmuş toprak örneklerinin yarayışlı fosfor (YP) içerikleri sodyum bikarbonat metodu ile belirlenmiştir (Olsen et al 1954).

\subsection{Istatistiksel analizler ve jeoistatistiksel modelleme}

Jeoistatistiğin temelleri ve uygulanması çeşitli kaynaklarda detaylı olarak sunulmuştur (Isaaks \& Srivastava 1989; Webster \& Oliver 2001; Goovaerts 1997). Jeoistatistik modelleme bu çalışmaların temel aracı olan semivariogramın hesaplanması ile başlar. Deneysel semivariogram bir $\mathrm{h}$ ayrım mesafesindeki tüm gözlemler arasındaki mekansal bağımlılığı ifade eder ve şu şekilde hesaplanır edilir (Isaaks \& Srivastava 1989):

$$
\lambda *(h)=\frac{1}{2 N(h)} \sum_{i=1}^{N(h)}\left[z\left(x_{i}\right)-z\left(x_{i}+h\right)\right]^{2}
$$

Burada $\lambda^{*}(h), \quad$ semivaryans değeri; $N(h)$, birbirinden $h$ uzaklıkta olan veri çiftlerinin sayısı; $z\left(x_{i}\right)$, değişkenin $i$ noktasındaki ölçülen değeri ve $z\left(x_{i}+h\right)$, ise değişkenin $x_{i}+h$ noktasındaki ölçülen değeridir.

Jeoistatistik enterpolasyon (kriging) mekansal 
olarak bağımlı değişkenlerin haritalanmasında en iyi linear yansız tahmini sağlar ve şu şekilde ifade edilir (Isaaks \& Srivastava 1989; Webster \& Oliver 2001):

$$
z\left(x_{0}\right)=\sum_{i=1}^{n} \lambda_{i} z\left(x_{i}\right)
$$

Eşitlik 2'de, $z\left(x_{o}\right), x_{o}$ noktasında değeri bilinmeyen fakat enterpolasyon ile bulunacak değeri; $z\left(x_{i}\right), x_{o}$ noktasındaki değerinin tahmininde kullanılacak komşu değerleri ve $\lambda_{i}$, bu verilere atanacak ağırlıkları ifade etmektedir.

Kriging lokal doğruluğu amaçlamakta bunu da tahminde kovaryans temelli hata varyansinı en düşük tutarak gerçekleştirmektedir. Oysa simulasyon tekniği spatial yapıyı kovaryans modeli yoluyla tekrar üretmeyi amaçlamaktadır. Kriging, tek bir harita çıktısı üretilirken simulasyonlar ile incelenen özelliğin spatial dağılımına ait çok sayıda realizasyonlar üretilir ve simulasyon haritaları arasındaki fark belirsizliğin ölçüsü olarak kullanılır (Desbarat 1996; Loague \& Kyriakidis 1997; Goovaerts 1997).

Ardışık Gauss Simulasyonu uygulanması, şu aşamalarla gerçekleştirilmektedir (Webster \& Oliver 2007; Vann et al 2002):

1-Verinin normal dağılıma sahip olduğundan emin olmak, aksi durumda veriyi standart normal dağılıma dönüştürmek,

2-Semivariogramın modellenmesi,

3-Simulasyon yapmak istediğiniz noktaların koordinatlarını belirlemek, (genellikle grid deseninde olmaktadır),

4-Simulasyon için dikkate alınacak (ziyaret edilecek) noktaların sırasını belirlemek, (Noktaları rasgele seçmek realizasyonlar arasındaki farklılığ maksimize etmektedir),

5-Her bir noktada simulasyon şu şekilde gerçekleştirilmektedir;

$\hat{\mathrm{Z}}\left(\mathrm{x}_{i}\right)$ ve $\sigma_{K}^{2}\left(\mathrm{x}_{i}\right)$ elde etmek için simple kriging yöntemini kullanılarak semivariogram modellenir ve transforme edilen normal dağılımdan $N\left(\hat{\mathrm{Z}}\left(\mathrm{x}_{i}\right)\right.$ ve $\left.\sigma_{\boldsymbol{R}}\left(\mathrm{x}_{i}\right)\right)$ rasgele bir değer çekilir. Bu değeri $\mathrm{x}_{i}$ noktasındaki grid değeri olarak atanır ve veriye ilave edilir. İşlemi bir sonraki noktada devam edilir ve tüm noktalar simüle edilene kadar işleme devam edilir,

6-Simüle edilen değerler geriye transforme edilir. Ardışık gauss simulasyon istenilen sayıda tekrar ettirilir. Sonuçta her bir simülasyonda farklı bir yol ile her bir nod noktasinın ziyaret edilmesi ile istenilen sayıda eşit olasılıklı realizasyonların elde edilmesini sağlar.

\subsection{Veri analizi}

Verilerin değerlendirilmesinde öncelikle YP'a ait veride tanımsal veri analizi yapılmıştır. Jeoistatistiksel modellerin oluşturulmasında ve tüm haritalama işlemlerinde ArcGIS 9.3 (ESRI 2006) programı kullanılmıştır. Çalışma alanı doğu-batı doğrultusunda $35 \mathrm{~km}$ ve kuzey-güney doğrultusunda ise 3 ile $9.5 \mathrm{~km}$ arasında değişen boyutlara sahiptir. $\mathrm{Bu}$ nedenle jeoistatistiksel değişkenliğin modellendiği semivariogramların oluşturulmasında $7.5 \mathrm{~km}$ maksimum mesafe olarak kullanılmıştır. Semivariogram modellenmesi öncesi veride trend olup olmadığ kontrol edilmiş ve trend göstermesi durumunda semivariogram modellemesi trend kaldırılan veride yapılmıştır. Farklı lag mesafelerinde farklı semivariogram modelleri seçilmiş ve her seçilen model için yönsel semivariogram modelleri ayrı ayrı denenmiştir.

Haritaların üretilmesinde ordinary kriging metodunda maksimum 20 komşu nokta olacak şekilde haritalar üretilmiştir. Her bir özellik için denenen semivariogram modellerine ait haritalar üretilerek haritaların hata değerleri kayıt edilmiş ve doğru modelin seçiminde bu değerler birbirleri ile kıyaslanmıştır. ArcGIS 9.3 "Geostatistical Analyst" programı ile üretilen haritalarda tahminin ortalama hatası $(M E)$ ve tahminin standardize ortalama hatalar karekökü (RMSSE) kriterlerini en iyi model seçiminde kullanmaktadır. En doğru harita oluşturulurken tahminin ortalama hatasi 0 'a yakın ve tahminin standardize ortalama hatalar karekökü ise 1'e yakın olmalıdır (Johnston et al 2001). Yarayışlı fosfor için en uygun modeller seçilerek haritalar üretilmiştir. Oluşturulan nihai haritalar $100 \times 100 \mathrm{~m}$ 'lik raster formatına dönüştürülüp arazinin sinırları boyunca bu raster katmanı 
kesilip lejantlar eklenmiştir. Ardışık gauss similasyon haritaları ArcGIS programına ait Arctoolbox araçları kullanılarak toplam 10 simülasyon olacak şekilde üretilmiştir. Ordinary Kriging ve AGS haritaları son aşamada spatial analiz modulünde FAO (1990)'a ait YP düzeyleri kullanarak sınıflandırılmış ve alansal büyüklükleri belirlenmiştir. Tüm tahmin, simulasyon ve yeniden sinıflama haritaları $100 \times 100 \mathrm{~m}$ (1 ha mekansal çözünürlük) piksel boyutundadır.

\section{Bulgular ve Tartışma}

\subsection{Tanımlayıcı istatistik}

Çalışma alanı Kazova üst topraklarında yarayışlı fosfor miktarı (YP) 1.54 ile $40.52 \mathrm{mg} \mathrm{kg}^{-1}$ arasında değişmekte olup ortalama $14.18 \mathrm{mg} \mathrm{kg}^{-1}$ dir. YP düzeyi $30-60 \mathrm{~cm}$ 'de ise ortalama $8.87 \mathrm{mg}$ $\mathrm{kg}^{-1}$ olup (1.78 ile $37.90 \mathrm{mg} \mathrm{kg}^{-1}$ arası değişmekte) üst topraktaki YP alt toprağa göre yaklaşık iki kat fazladır. Bağımsız t testi sonuçlarına göre üst ve alt toprak YP düzeyleri arasındaki fark önemlidir $(P<0.01)$ (Çizelge 1). Üst toprakta ortalama YP miktarı FAO (1990) göre yeterli, Ülgen \& Yurtsever (1974)'e göre orta olarak sinıflandırılmaktadır. Eyüpoğlu (1999) yaptığı çalışmada Tokat yöresinden alınan 4195 toprak örneğinin \%73.3'ünde YP miktarının az ve çok az $\left(<6 \mathrm{~kg} \mathrm{P}_{2} \mathrm{O}_{5} \mathrm{da}^{-1} ;<10.8 \mathrm{mg} \mathrm{P} \mathrm{kg}^{-1}\right)$ olduğunu bildirmiştir. Tokat, Toprak ve $\mathrm{Su}$ Araştırma Enstitüsü laboratuarında 2000 ile 2003 yılları arasında yapılan 6889 adet çiftçi toprak örneğinin \%53'ünde (3682 örnek) YP miktarının yetersiz olduğu $\left(<10.8 \mathrm{mg} \mathrm{kg}^{-1} \mathrm{P}\right.$ daha düşük) rapor edilmiştir (Tetik \& Oğuz 2004). Saltalı et al (2004), Kazova topraklarında bilinçsiz gübreleme neticesinde önemli düzeyde fosfor birikiminin olduğunu ortaya koymuşlardır. Bu çalışma ve Saltalı et al (2004) ait YP ait sonuçlar Kazova topraklarında YP miktarının önceki araştırma sonuçlarına göre zaman içinde artış gösterdiğini ortaya koymaktadır. $\mathrm{Bu}$ durumun muhtemel nedeni çiftçilerin toprak analizi sonuçlarına göre değil kendi deneyim ve gözlemlerine dayanarak gübreleme uygulamasina devam etmeleridir. Kazova'da üretim yapan 156 tarım işletmesinde yürütülmüş bir araştırmanın sonuçları da bu bulguları desteklenmektedir. Bu çalışmaya göre
Kazova'da işletme sahiplerinin \%64.5'i toprak analizi yaptırmayı ihmal ettikleri veya hiç düşünmediklerini belirtmişler ve gübrelemede kendi deneyimlerini toprak analiz sonuçlarına tercih ettiklerini beyan etmişlerdir (Yarar 2004).

Camberdella et al (1994) toprak değişkenliğini varyasyon katsayısına (VK) göre 3 sinıfa ayırmışlardır. Buna göre VK'sı \%15'den küçük olanlar az değişken, \%16-35 arasında olanlar orta derecede değişken ve \%36'dan büyük olanlar ise yüksek derecede değişken olarak gruplandırılmıştır. VK değerlerine göre her iki derinlikte de YP'a ait VK değerleri birbirine oldukça yakın olup yüksek derecede değişkendir. Çalışma alanında üst toprakta YP 1.02'lik yatıklık değerine sahip iken alt toprakta $(30-60 \mathrm{~cm})$ yatıklık değeri 2.41'e yükselmektedir. Alt toprakta YP'un ortalaması $8.87 \mathrm{mg} \mathrm{kg}^{-1}$ iken, 20 $\mathrm{mg} \mathrm{kg}{ }^{-1}$, dan yüksek değerlerin daha fazla sayıda olması yatıklık değerinin üst toprağa göre iki kat fazla olmasına yol açmıştır. Aynı şekilde YP'a ait basıklık değerleri alt toprakta üst toprağa göre daha yüksek olup her iki derinlikte de YP'a ait dağılımlar normal dağılımdan farklıdır (Şekil 2).

$\mathrm{Bu}$ çalışma için toprak örneklemesi yapıldığ dönemde, örnek noktalarının 255'inde tarla bitkileri, 73'ünde sebze, 72 tanesinde ise diğer kullanım (mera, meyvelik, yem bitkileri ve sürülmüş boş arazi) türlerinin uygulandığı belirlenmiştir. Çalışma alanında en fazla kullanım çeşidi tarla bitkileri ve sebze yetiştiricili olup (yaklaşık \%75'i 400 noktadan 328'inde), her iki tarım uygulamasında da bitki fosfor ihtiyacı gübreleme yolu ile karşılanmaktadır. Çizelge 2'de en yaygın iki kullanım türüne ait YP miktarları verilmiştir. Tüm alan için üst topraktan alınan 400 toprak örneğinin ortalama YP miktarı 14.18 $\mathrm{mg} \mathrm{kg} \mathrm{kg}^{-1}$ iken sebze yetiştiriciliği yapılan alanlardan alınan örneklerin ortalama YP düzeyi daha yüksek olup $19.20 \mathrm{mg} \mathrm{kg}^{-1}$ düzeyindedir. Aynı zamanda sebze yetiştiriciliği yapılan alanlarda tarla bitkileri üretimi yapılan alanlara göre YP miktarları her iki derinlikte de daha yüksektir. Sebze yetiştiriciliği yapılan alanlarda birim alana daha fazla fosforlu gübre kullanması bu alanlardaki YP düzeylerindeki artışın 
Çizelge 1-Kazova topraklarının YP düzeylerine ait $\left(\mathrm{mg} \mathrm{kg}^{-1}\right)$ ait tanımlayıcı istatistik sonuçları Table 1-Descriptive statistics of YP $\left(\mathrm{mg} \mathrm{kg}^{-1}\right)$ in Kazova soils

\begin{tabular}{|c|c|c|c|c|c|c|c|}
\hline & En düşük & En yüksek & Aritmetik ortalama & Standart sapma & $V K^{1}, \%$ & Yatıklık & Basıklık \\
\hline$\overline{\mathrm{YP}}(0-30 \mathrm{~cm})$ & 1.54 & 40.52 & $14.18 \mathrm{a}$ & 8.47 & 59.73 & 1.02 & 0.38 \\
\hline YP $(30-60 \mathrm{~cm})$ & 1.78 & 37.90 & $8.87 \mathrm{~b}$ & 5.06 & 57.05 & 2.41 & 7.94 \\
\hline
\end{tabular}
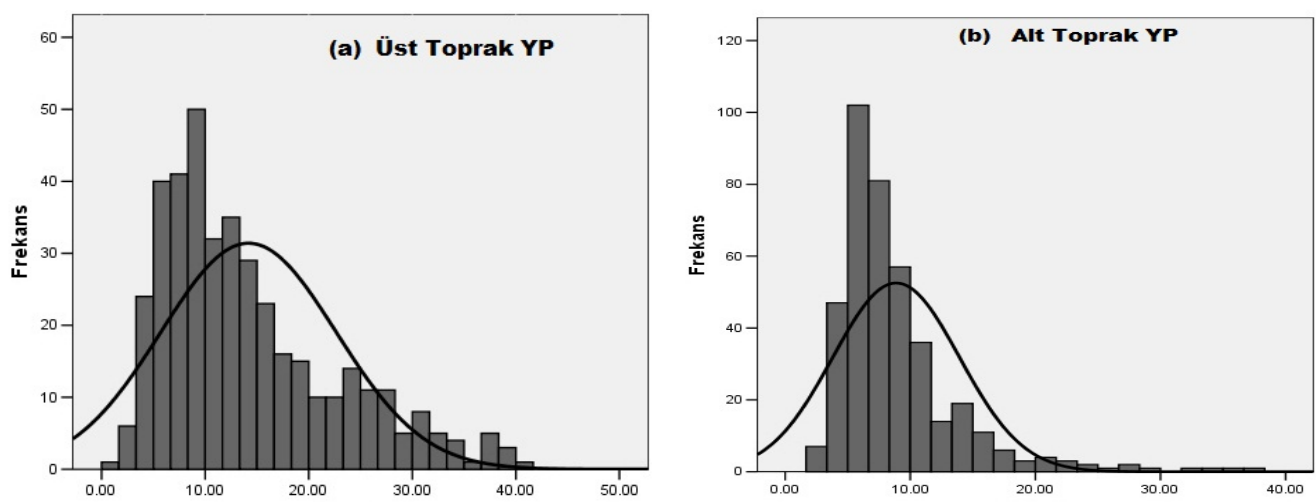

Şekil 2-Üst ve alt toprakta YP'a ait histogramlar (a) Üst toprak YP (0-30 cm), (b) Alt toprak YP (30-60 cm) Figure 2-Histograms of YP in topsoil and subsoil (a) Topsoil YP (0-30 cm), (b) Subsoil YP (30-60 cm)

muhtemel nedenidir. Farklı yetiştiricilik uygulanan (sebze ve tarla bitkileri) alanların her ikisinde de üst ve alt toprak YP düzeyleri arasındaki fark önemlidir $(P<0.01)$ (Çizelge 2).

\subsection{Haritalama}

Yarayışlı fosfor içeriklerine ait verilere logaritmik transformasyon yapıldıktan sonra jeoistatistik modellemeler yapılmıştır. Ancak bu şekilde üretilen haritaların hata değerleri daha yüksek bulunmuştur. $\mathrm{Bu}$ nedenle YP'a ait ordinary kiriging (OK) haritaları üretilirken veride herhangi bir transformasyon yapılmamıştır. Çalışma alanında üst toprakta YP doğu-batı yönünde bir trend göstermekte olup batıya doğru gidildikçe fosfor miktarı düşmektedir. Bu nedenle üst toprak YP için semivariogram modellenmesi öncesinde veriden birinci dereceden global trend kaldırılmıştır. $\mathrm{Bu}$ şekilde üretilen haritalarda daha düşük hata değerleri elde edilmiştir. YP çalışma alanında herhangi bir yönsel değişim göstermediğinden izotropik semivariogram modelleri haritaların üretilmesinde kullanılmıştır.
Her iki derinlik içinde üssel semivariogram modeli çalışma alanının YP değişimini en iyi temsil etmiştir ve OK haritalarının üretilmesinde kullanılmıştır (Çizelge 3). Nugget semivaryansın toplam semivaryansa oranının yüzde olarak ifadesi toprak değişkenlerinin uzaysal bağımlılı̆̆ın sınıflandırılmasında kullanılmaktadır. Ĕger bu oran $\leq \% 25$ ise değişken kuvvetli uzaysal bağımlı olarak sınıflandırılmakta, $\% 25$ ile $\% 75$ arasında ise orta derecede uzaysal bağımlı olarak sinıflandirılmaktadır. $\mathrm{Bu}$ oran \% 75 'den fazla ise değişken zayıf uzaysal bağımlı olarak siniflandırılmaktadır (Cambardella et al 1994). Modellenen semivariogramlar için hesaplanan nugget oranına (\%) göre, YP çalışma alanın üst ve alt topraklarında orta derecede uzaysal bağımlılık göstermektedir. YP ait semivariogramlara ait parametreler Çizelge 3'de verilmiştir.

Kazova'da YP miktarının üst ve alt topraktaki değişiminin $\mathrm{OK}$ tahmin yöntemine göre üretilmiş tahmin haritaları sırasıyla Şekil $3 a$ ve $3 c^{\prime}$ de 
Çizelge 2-Yetiştiricilik türlerine göre YP $\left(\mathrm{mg} \mathrm{kg}^{-1}\right)$ miktarları ait tanımlayıcı istatistik değerleri Table 2-Descriptive statistics of $Y P\left(\mathrm{mg} \mathrm{kg}^{-1}\right)$ in different land use

\begin{tabular}{|c|c|c|c|c|c|c|c|}
\hline & En düşük & En yüksek & Aritmetik ortalama & Standart sapma & $V K^{1}, \%$ & Yatıklık & Basıklık \\
\hline & \multicolumn{7}{|c|}{ Sebze yetiștiriciliği yapılan alanlar $(\mathrm{n}=73)$} \\
\hline Üst toprak YP & 4.36 & 40.52 & $19.40 \mathrm{a}$ & 9.94 & 51.24 & 0.53 & -0.85 \\
\hline \multirow[t]{2}{*}{ Alt toprak YP } & 3.04 & 37.90 & $12.04 \mathrm{~b}$ & 6.98 & 57.97 & 1.55 & 2.72 \\
\hline & \multicolumn{7}{|c|}{ Tarla bitkileri yetiștiriciliği yapılan alanlar $(\mathrm{n}=225)$} \\
\hline Üst toprak YP & 3.03 & 38.97 & $13.80 \mathrm{a}$ & 7.66 & 55.51 & 1.05 & 0.52 \\
\hline Alt toprak YP & 1.78 & 35.12 & $8.53 \mathrm{~b}$ & 4.38 & 57.97 & 2.62 & 10.15 \\
\hline
\end{tabular}

${ }^{1}$ VK; Varyasyon Katsayıs 1

${ }^{\mathrm{a}-\mathrm{b}}$; Aynı sütunda yer alan ortalamalar arasındaki farklılıklar istatistik önemlidir $(P<0.05)$

Çizelge 3-YP ait isotropik semivariogramların parametreleri ve modellerin hata değerleri $(n=400)$

Table 3-Isotropic semivariogram parameters of YP and error of models

\begin{tabular}{|c|c|c|c|c|c|c|c|}
\hline & Model & Nugget, Co & Sill, $C o+C s$ & Range, $m$ & Nugget/Sill, \% & $M E^{1}$ & $R M S S E^{2}$ \\
\hline $\begin{array}{l}\text { Üst toprakYP }{ }^{\&} \\
0-30 \mathrm{~cm}\end{array}$ & $\begin{array}{l}\text { Exponential } \\
\text { Üssel } \\
\end{array}$ & 20.00 & 57.84 & 1196.12 & 34.57 & 0.03149 & 1.004 \\
\hline $\begin{array}{l}\text { Alt toprak YP } \\
30-60 \mathrm{~cm}\end{array}$ & $\begin{array}{l}\text { Exponential } \\
\text { Üssel }\end{array}$ & 5.00 & 18.49 & 546.07 & 27.03 & -0.03519 & 1.108 \\
\hline
\end{tabular}

verilmiştir. Aynı haritalar fosfor düzeylerindeki farklıkları görmek açısından YP seviyelerine göre FAO (1990)'a göre yeniden sınıflandırılmıştır (Şekil 3b ve 3d). Bu sinıflamaya göre $2.5 \mathrm{mg} \mathrm{kg}^{-1}$ YP düzeyi "çok az", $2.5-8.0 \mathrm{mg} \mathrm{kg}^{-1}$ arası "az", $8.0-25 \mathrm{mg} \mathrm{kg}^{-1}$ "yeterli” ve $25-80 \mathrm{mg} \mathrm{kg}^{-1}$ arası ise "fazla" olarak sinıflandırılmaktadır. Çalışma alanının üst topraklarının YP miktarları ovanın doğu kesimi ile batı kesimi arasında büyük farklılık göstermektedir. Ovanın yoğun sebze üretimi özellikle sırık domates yetiştiriciliği yapılan arazilerin yer aldığı doğu kesiminde YP miktarı diğer bölgelere göre oldukça yüksektir. $\mathrm{Bu}$ alanlarda üst topraktaki YP miktarı $35 \mathrm{mg} \mathrm{kg}^{-1}$ değerine kadar ulaşmaktadır. Üst toprak için yapılan sinıflama haritasında (Şekil 3b) topraklarda YP miktarı fazla olarak sinıflandırılan araziler çalışma alanının doğu ve güneydoğu kesimlerinde yer almaktadır. Yeniden sinıflama ile üretilen haritada (Şekil 3b) Kazova yüzey topraklarının \% 82.16'inde yeterli düzeyde YP bulunduğu görülmektedir (Çizelge 4). Aynı haritada çalışma alanı üst topraklarının \% 11.56'lık bölümünde YP miktarları az ve \% 6.28'lik kısmında ise fazla olarak sınıflandırılmıştır.

Çalışma alanın alt toprakta YP düzeyi bakımında fazla olarak $\left(25-80 \mathrm{mg} \mathrm{kg}^{-1} \mathrm{P}\right)$ siniflandırılan arazi yok denecek kadar azdir. Arazilerin yaklaşık yarısı (\% 55.33) yeterli düzeyde YP içerirken, \% 44.61 lik kesiminde YP düzeyi az olarak sınıflandırılmıştır (Şekil 3d ve Çizelge 4). Alt toprak için YP düzeyi yeterli olan araziler Kazova'nın genellikle doğu kesimlerinde yer alırken, YP düzeyi az olarak sınıflandırılan araziler orta ve doğu bölgelerinde yer almaktadır.

Kazova üst ve alt toprak YP düzeyi için hazırlanan AGS haritaları Şekil 4'de verilmiştir. AGS metoduna çalışma alanında üst toprakta YP düzeyi az olarak sınıflanan alanlar $\% 9.98$, yeterli olarak sinıflanan alanlar \% 86.16 ve fazla olarak sinıflanan alanlar ise \% 3.75 olarak belirlenmiştir (Çizelge 4). Alt toprak YP miktarı ise çalışma alanının \% 37,96'lık kesiminde az ve \% 62.3'lik kısmında ise yeterli olarak sınıflandırılmıştır (Çizelge 4). 


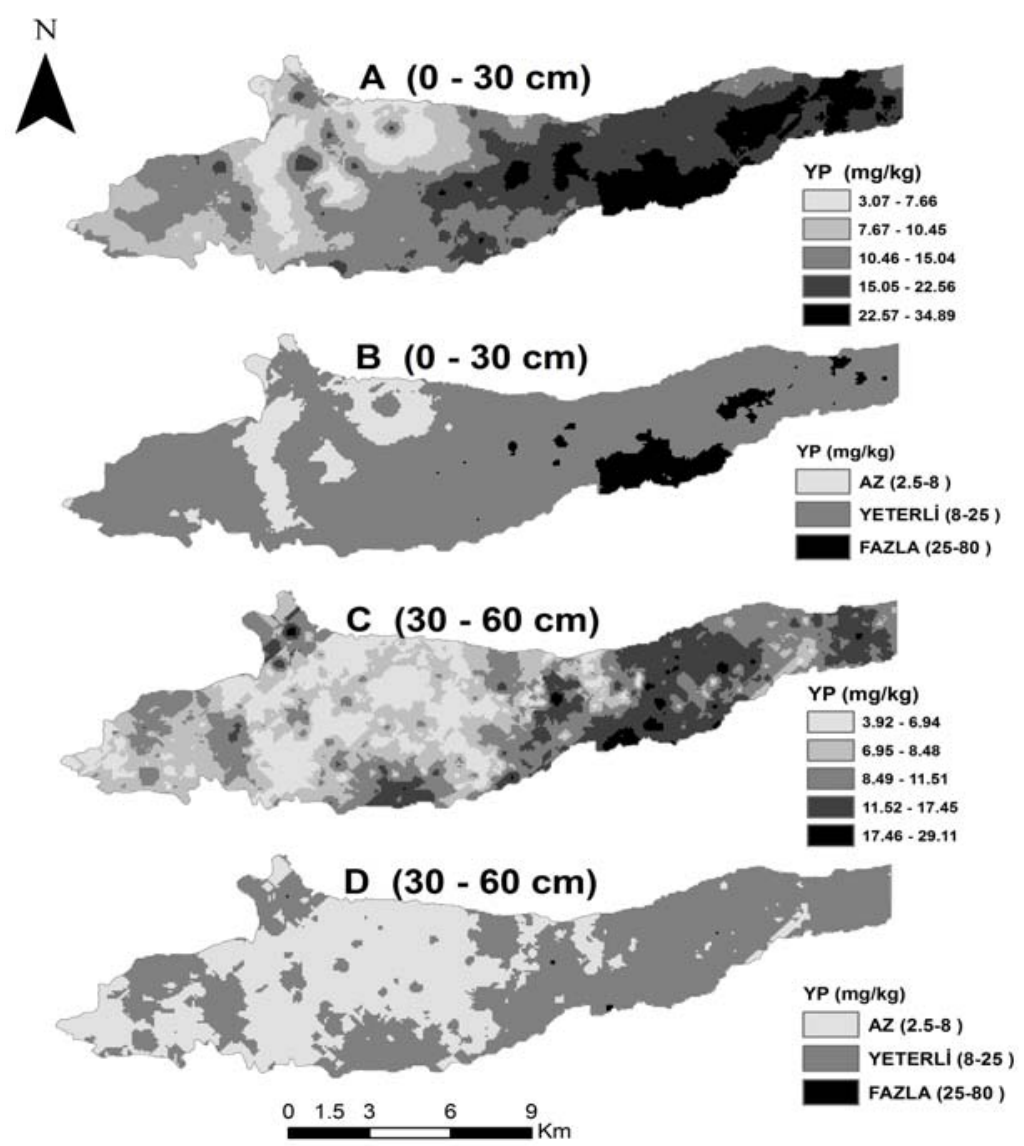

Şekil 3-Çalışma alanın YP'un OK ve sınıflama haritaları (A)Üst toprak OK, (B) Üst toprak sınıflanmış OK sonucuna gore, (C) Alt toprak OK, (D) Alt toprak sınıflanmış OK sonucuna göre

Figure 3-OK and classification map of YP in the study area (A) OK topsoil, (B) classified OK maps of topsoil, (C) OK map of subsoil, (D) classified OK maps of subsoil

Çizelge 4-OK ve AGS yöntemleri ile hazırlanan haritaların YP düzeylerine karşılık gelen $\%$ alan miktarları

Table 4-The area of the different YP levels of maps prepared with OK and AGS methods

\begin{tabular}{|c|c|c|c|c|}
\hline \multirow[t]{2}{*}{ YP düzeyi } & \multicolumn{2}{|c|}{$\begin{array}{c}\ddot{U} \text { st toprak }(0-30 \mathrm{~cm}) \\
\text { Alan }(\%)\end{array}$} & \multicolumn{2}{|c|}{$\begin{array}{c}\text { Alt toprak }(30-60 \mathrm{~cm}) \\
\text { Alan }(\%) \\
\end{array}$} \\
\hline & $\mathrm{OK}$ & AGS-ort & $\mathrm{OK}$ & AGS-ort \\
\hline $\mathrm{Az}$ & 11.56 & 9.98 & 44.61 & 37.96 \\
\hline Yeterli & 82.16 & 86.27 & 55.33 & 62.31 \\
\hline Fazla & 6.28 & 3.75 & 0.06 & - \\
\hline
\end{tabular}




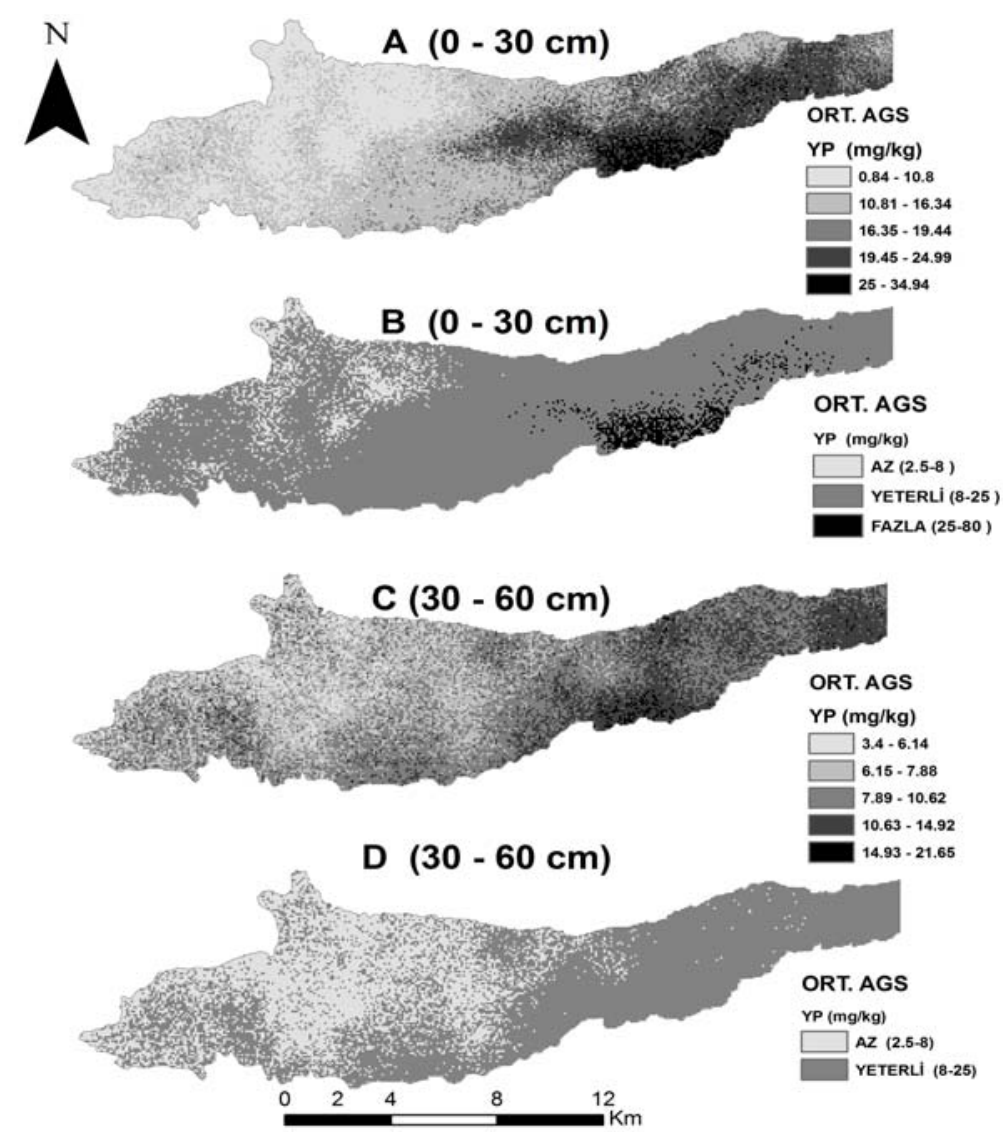

Şekil 4-Çalışma alanın YP'un AGS ve sınıflama haritaları (A)Üst toprak AGS, (B) sınıflanmış üst toprak, (C) Alt toprak AGS, (D) sınıflanmış alt toprak

Figure 4-AGS and classification map of YP in the study area (A) AGS map of topsoil, (B) classified AGS map of topsoil, (C) AGS map of subsoil, (D) classified AGS map of subsoil

Şekil 3 \& 4'de verilen OK ve AGS haritaları genel değişkenlik deseni dikkate alınarak değerlendirildiğinde yüksek ve düşük YP düzeyleri büyük benzerlik göstermektedir. Ancak kısa mesafe değişkenliğini temsil etmede AGS haritaları OK haritalarına göre daha başarılı olduğu görülmüştür. AGS ile üretilen haritalarda OK metoduna göre lokal detayların daha belirgin hale geldiği görülmektedir (Şekil $4 \mathrm{a} \& 4 \mathrm{c}$ ). Daha önceki çalışmalarda da OK yönteminin sonuçları yumuşatma etkisinden dolayı lokal detayları yansitmada yetersiz olduğu ve AGS ile üretilen simülasyon haritalarının lokal değişimi daha doğru yansıttığı bildirilmiştir (Grunwald et al 2007; Meirvenne \& Goovaerts 2001)

Üst toprak için AGS haritasının yeniden sınıflandırılması ile elde edilen haritada (Şekil 4b) YP düzeyinin az ve fazla olduğu kesimler $\mathrm{OK}$ kriging metodu ile üretilen haritaya göre alansal olarak azalırken yeterli olduğu kesimler artmıştır (Çizelge 4). Çalışma alanı alt toprakları içinde aynı durum söz konusu olup AGS ile üretilen haritada YP düzeyi "az" olarak sinıflandırılan alan azalırken "yeterli" olarak sinıflandirılan alan artmıştır (Şekil 4d \& Çizelge 4). 
OK ve AGS-ort haritalarının YP değerlerine ait dağılımların parametreleri üç tane örnek AGS'na ait değerler ile birlikte Çizelge 5'de verilmiştir. AGS-ort şeklinde sunulan değerler 10 simülasyonun ortalamasına ait değerlerdir. Örnek olarak verilen üç simülasyonda (AGS-1, AGS-2, AGS-3) üst ve alt toprak için her bir simulasyon veri seti ile aynı değişim aralığındadır. Örnek olarak verilen 3 simulasyonda (AGS-1, AGS-2, AGS-3) yüksek ve düşük değerin tamamı veri setinde yer almıştır. AGS-ort için verilen değerler ise veri setinden daha dar bir aralıkta yer almakdır. Ortalama AGS haritaları oluşturulurken yüksek değerlerin az sayıda pikselde yer alması ve her bir piksel için üretilen simulasyon değerlerinin ortalaması alındığı için yuvarlama etkisi oluşmaktadır. Ordinary Kriging tahmin metotu ve
AGS-ort haritalarının YP değerlerine ait aritmetik ortalama değerleri orijinal veri setinin ortalama değerine oldukça yakındır. OK ve AGS-ort haritalarının veri setlerinin her ikisinde de standart sapma değerleri orijinal veri setine göre daha düşüktür. $\mathrm{Bu}$ durumun diğer bir göstergesi en düşük ve en yüksek değerlerin orijinal veriye göre daha dar bir aralığa gelmiş olmasıdır. Bu da her iki haritalama metodunda da (OK ve AGS-ort) düşük ve yüksek değerlerin yuvarlama etkisine maruz kaldığını göstermektedir. Üst ve alt toprak için üretilen simulasyonlardan örnek olarak verilen 3 tanesinin (AGS-1, AGS-2, AGS-3), standart sapma değerleri orijinal veri setine oldukça yakın olup OK ve AGS-ort göre daha yüksektir (Çizelge 5).

\section{Çizelge 5-Veri seti, OK ve AGS yöntemleri ile üretilen haritalarının YP (mg kg $\left.{ }^{-1}\right)$ değerlerine ait dağılımın parametreleri \\ Table 5-Distribution parameters of data set, OK and AGS maps of YP ( $\left.\mathrm{mg} \mathrm{kg}^{-1} 1\right)$}

\begin{tabular}{lllllll}
\hline & \multicolumn{2}{l}{ Üst toprak YP $(0-30 \mathrm{~cm})$} & \multicolumn{3}{l}{ Alt toprak YP $(30-60 \mathrm{~cm})$} \\
\cline { 2 - 7 } & \multicolumn{2}{l}{ Ortalama (Min- Maks) [Stan.Sapma] } & \multicolumn{3}{c}{ Ortalama (Min- Maks) [Stan.Sapma] } \\
\cline { 2 - 7 } Veri seti & 14.18 & $(1.54-40.52)$ & {$[8.47]$} & 8.87 & $(1.78-37.90)$ & {$[5.06]$} \\
OK & 14.64 & $(3.07-34.89)$ & {$[6.03]$} & 9.17 & $(3.92-29.11)$ & {$[2.92]$} \\
AGS-ort & 14.48 & $(3.04-34.94)$ & {$[5.44]$} & 8.97 & $(3.40-21.65)$ & {$[2.26]$} \\
AGS-1 & 13.95 & $(1.54-40.52)$ & {$[8.08]$} & 9.38 & $(1.78-37.90)$ & {$[5.22]$} \\
AGS-2 & 14.77 & $(1.54-40.52)$ & {$[8.37]$} & 9.25 & $(1.78-37.90)$ & {$[5.09]$} \\
AGS-3 & 14.35 & $(1.54-40.52)$ & {$[8.22]$} & 9.16 & $(1.78-37.90)$ & {$[5.03]$} \\
\hline
\end{tabular}

Alt toprak YP'a ait veri setlerinde $20 \mathrm{mg} \mathrm{kg}^{-1}$ in üstünde sadece 7 adet verinin olması AGS ile üretilen ortalama haritada bu değerlerin temsil edilememesine yol açmıştır. Üst toprakta ise aşırı değerlerin sayıca daha fazla olması (30'a yakın) bu değerlerin doğru temsil edilmesine neden olmuştur (Çizelge 5). Elde edilen bu sonuçlara benzer olarak, Lin et al (2001) tarafindan yürütülen toprak kurşun içeriği ile ilgili bir çalışmada, AGS ile üretilen her bir simulasyonun standart sapma değerlerinin orijinal veri setine oldukça yakın olduğunu ve OK metoduna göre veri setine daha yakın sonuçlar verdiğini bildirmişlerdir. Araştırıcılar, bu çalışma ile benzer dağılım parametrelerine (yatıklık, basılık) sahip olan toprak kursun içeriğine ait verinin OK metoduna göre hazırlanan tahmin haritasının veri seti ile benzer istatistik değerleri sağlamada başarısız olduğunu bildirmişlerdir. Grunwald et al (2004) toprakta toplam fosfor ile yürüttügüü çalışmada SGS metodu ile üretilen her bir simülasyonun örneğe ait istatistik değerlere (ortalama, standart sapma, histogram) sahip haritalar ürettiğini ve bu yönüyle OK metoduna önemli bir alternatif olabileceğini bildirmişlerdir. SGS ile üretilen her simülasyonun uzaysal yapı ve istatistik parametrelere bakımından veri setine büyük benzerlik gösterdiği için özellikle risk değerlendirme ve uzaysal belirsizlik (spatial uncertainty) çalışmalarında tercih edilebileceğini belirtmişlerdir. 


\section{Sonuçlar}

Kazova'da yer alan tarim arazilerinde YP miktarları artma eğiliminde olup üst toprak (0-30 $\mathrm{cm})$ için alanın yaklaşık \%80'inde yeterli seviyededir. Sonuçlar tarımsal üretimde fosforlu gübrelerin kullanımında daha dikkatli olunması gerektiğine işaret etmektedir. Toprak analiz sonuçları dikkate alınarak yetiştirilecek ürüne uygun gübre çeşit ve dozunun tavsiye edilmesi ve uygulanması sürdürülebilir bir tarım sistemi için mutlak gereklidir. Böylece gereksiz gübre kullanımından dolayı ekonomik kayıp engellenecek ve fosforlu gübrelerin çevreye zarar verme risklerini ( $\mathrm{Cd}$ birikmesi ve ötröfikasyon) en aza indirecektir.Bu çalışma ile Kazova topraklarının YP miktarının değişimi OK ve AGS yöntemleri ile haritalanmıștır. Genel durumu yansıtmada her iki metod da benzer sonuçlar vermesine rağmen, ortalama simülasyon sonucunun değerlendirmede kullanılmasından dolayı AGS-ort haritalarında "az" ve "fazla" YP düzeylerine sahip alanlar daha düşük tahmin edilmiştir. AGS yöntemiyle üretilen her bir simülasyon veri ile aynı istatistik parametrelere sahip olup, OK metoduna göre tahminde daha başarı bulunmuştur. Uygun ve yeterli kalitede ürünü garanti altına almak için üretilen minimum simülasyon haritaları, aşırı fosfor kullanımını engellemek için ise maksimum simülasyon haritaları karar verme açısından tercih edilebilir. Belirli sınır değerlerinin belirlenip o sınır değerleri üstünde kalacak alanların olasılık değerlerinin üretildiği AGS haritaları ile YP düzeyinin düşük ve fazla olduğu alanların arazide bulunabilme olasılıklarını görmek mümkün olacaktır.

\section{Teşekkür}

$\mathrm{Bu}$ çalışmada toprak örneklemesi ve toprak analizleri TUBITAK TOVAG tarafindan desteklenen proje kapsamında yapılmıştır ( Proje No: 105 O 617).

\section{Kaynaklar}

Alpaslan M, Güneş A \& İnal A (1998). Deneme Tekniği. Ankara Üniversitesi Ziraat Fakültesi Yayın No: 1501, Ders Kitab1, 455, Ankara
Brady N C (1990). The Nature and Properties of Soils. 10th edition. Mac Millan Pub. Comp. $621 \mathrm{~s}$

Cambardella C A, Moorman T B, Novak J M, Parkin T B, Karlen D L, Turco R F \& Konopka A E (1994). Field -scale variability soil properties in Central Iowa Soils. Soil Science Society America.Journal 58:1501-1511

Caridad-Cancela R, Vazquez E V, Vieira S R, Abreu C A \& Paz Gonzalez A A (2005). Assessing the spatial uncertainty of mapping trace elements in cultivated fields. Communications In Soil Science and Plant Analysis 36: 253-274

Çimrin K M \& Boysan S (2006). Van yöresi tarım topraklarının besin elementi durumları ve bunların bazı toprak özellikleri ile ilişkileri. Yüzüncü Yll Üniversitesi, Ziraat Fakültesi, Tarım Bilimleri Dergisi 16(2): 105-111

Desbarat A J (1996). Modelling spatial variability using geostatistical simulation. Geostatistics For Environmental And Geotechnical Applications, S. Srivastava et al. (eds). ASTM STP 1283, Am. Soc. Testing and Materials:West Conshohocken, PA; $32-48$

Dinç U, Şenol S, Sayın M \& Kapur S, (1988). Güneydoğu Anadolu Bölgesi Toprakları (GAT) I. Harran Ovası, TÜBİTAK, Tarım Ormancılık Araştırma Grubu, Güdümlü Araştırma Projesi Kesin Sonuç Raporu, TAOG, 534, Adana

DMI (2007). Devlet Meteoroloji işleri Genel Müdürlüğü, Tokat Meteoroloji İstasyonu verileri

Eyüpoğlu F (1999). Türkiye Topraklarının Verimlilik Durumu. Toprak Gübre Araş. Enst. Genel Yayınları No: 220, Ankara

ESRI (2006). ArcGIS 9.3 Environmental System Research Institute. Redland CA,USA.

FAO (1990). Micronutrient, Assessment at the Country Level: An International Study. FAO Soil Bulletin by Sillanpaa. Rome

Goovaerts P (1997). Geostatistics for Natural Resources Evaluation. Oxford University Press, New York

Goovaerts P (1999). Geostatistics in soil science: stateof-the-art and perspectives. Geoderma 89:1-45

Goovaerts P (2001). Geostatistical modeling of uncertainty in soil science. Geoderma 103:3-26

Johnston K, Hoef M, Krivoruchko K \& Lucas N (2001). Using ArcGIS geostatistical Analyst, New York, ESRI

Grunwald S, Reddy K R, Newman S \& DeBusk W F (2004) Spatial variability, distribution and 
uncertainty assessment of soil phosphorus in a south florida wetland. Environmetrics 15: 811-825

Grunwald S, Reddy K R Prenger J P \& Fisher M M (2007). Modeling of the spatial variability of biogeochemical soil properties in a freshwater ecosystem. Ecological Modelling 201:521-535

Isaaks E H \& Srivastava R M (1989). An Introduction to Applied Geostatistics. Oxford University Press: New York

Lin Y P \& Chang T S (2000). Geostatistical simulation and estimation of the spatial variability of soil zinc. Journal Of Environmental Science and Health, Part A 35(3):327-347

Lin $\mathrm{Y}$ P, Chang $\mathrm{T} \quad \mathrm{K}$ \& Teng $\mathrm{T}$ P (2001). Characterization of soil lead by comparing sequential gaussian simulation, simulated annealing simulation and kriging methods. Environmental Geology 41:189-199

Lin Y P, Teng T P \& Tan Y C (2001). Estimating and simulating spatial distribution of transmissivity using geostatistics methods. MODSIM 2001 International Congress on Modelling and Simulation Soc. of Australia and New Zealand, 1967-1972 s, ISBN :0-867405252

Loague K \& Kyriakidis P C (1997). Spatial and temporal variability in the R-5 infiltration data set: Dejavu and rainfall-runoffsimulations. Water Resources Research 33: 2883-2895

Meirvenne M V \& Goovaerts P (2001). Evaluating the probability of exceeding a site-specific soil cadmium contamination threshold. Geoderma 102: 75-100

Novinpour E A (1993). Tokat-Kazova'nın Hidrojeoloji İncelenmesi. Doktora tezi, Ankara Üniversitesi Fen Bilimleri Enstitüsü, Jeoloji Mühendisliği Ana Bilim Dal1, Ankara

Olsen S R, Cole C V, Watanabe F S \& Dean L A (1954). Estimation of available phosphorus in soils by extraction with sodium bicarbonate. US Dept. Agric. Cric. 939

Ryan J \& Rashid A (2005). Phosphorus. Rattan Lal (Ed.) Encyclopedia of Soil Science, $2^{\text {nd }}$ Edition CRC Press, pp 1275-1279

Saltalı K, Sarı H, Mendil D \& Altın S (2004). Cadmium and phosphorus accumulates in soil under intensive cultivation in Turkey. Acta Agriculturae Scandinavica, Section B -Plant Soil Science 54(4): 267-272

Soil Survey Staff (1999). Soil taxonomy: a basic system of soil classification for making and interpreting soil surveys, $2^{\text {nd }}$ edition. Agriculture Handbook, vol. 435.USDA, NRCS., US Government Printing Office, Washington DC

Shenoy V V \& Kalagudi G M (2005). Enhancing plant phosphorus use efficiency for sustainable cropping. Biotechnology Advances 23:501-513

Taban S, Çıkılı Y, Kebeci N T, Sağlam U, Keşkek E \& Sezer M (2010). Taşköprü yöresinde sarımsak tarımı yapılan toprakların bazı fiziksel ve kimyasal özellikleri ve sarımsağın gübrelenmesi www.Kastamonutarim.Gov.Tr/Cifmektup/Sarimsak / Sargubretaskop.Doc Erişim Tar:14.01.2010

Tetik A \& Oğuz İ (2004). Gübre uygulamalarında toprak analizinin önemi ve Tokat yöresi topraklarının bazı fiziksel ve kimyasal özellikleri ile besin elementi ihtiyaçlarıTürkiye 3 . Ulusal Gübre Kongresi Tarım Sanayi - Çevre. 153-166 s. 11-13 Ekim 2004, Tokat

Tisdale S L, Nelson W L, Beaton J D \& Havlin J L (1993). Soil Fertility and Fertilizers, 5th ed. $634 \mathrm{~s}$ Macmillan Publishing, New York

Turan M A, Katkat A V, Özsoy G \& Taban S (2010). Bursa ili alüviyal tarım topraklarının verimlilik durumları ve potansiyel beslenme sorunlarının belirlenmesi. Uludă Üniversitesi Ziraat Fakültesi Dergisi 24(1): 115-130

Ülgen N \& Yurtsever N (1974). Türkiye Gübre ve Gübreleme Rehberi. Toprak ve Gübre Araştırma Enstitüsü Teknik Yayın No:28, Ankara

Vann J , Bertoli O \& Jackson S (2002). An overview of geostatistical simulation for quantifying risk. In: Proceedings of the Geostatistical Association of Australasia Symposium "Quantifying Risk and Error" March 2002, Perth, Western Australia

Webster R \& Olivier M A (2001). Geostatistics for Environmental Scientists, J. Wiley \& Sons, Chichester, U.K

Webster R \& Oliver M A (2007). Geostatistics for Environmental Scientists $2^{\text {nd }}$ Edition. John Wiley \& Sons Chichester, U.K

Yarar R (2004). Tarım işletmelerinde ticari gübre tedariki ve kullanımda Tokat ili Kazova bölgesi örneği. Türkiye 3. Ulusal Gübre Kongresi, Tarım Sanayi -Çevre, 1107-1112. 11-13 Ekim 2004,Tokat

Yildız N \& Bilgin N (2008). Erzurum ovas1 topraklarının fosfor ve potasyum durumunun neubauer fide yöntemi ile belirlenmesi Atatürk Üniversitesi Ziraat Fakültesi. Dergisi 39(2): 159165. Erzurum

Zhao Y, Xu X, Darilek J L, Biao Huang B, Sun W \& 
Shi X (2009). Spatial variability assessment of soil nutrients in an intense agricultural area, a case study of Rugao County in Yangtze River Delta Region, China. Environmental Geology 57:1089-1102 